\title{
The importance of pollinators and autonomous self-fertilisation in the early stages of plant invasions: Banksia and Hakea (Proteaceae) as case studies
}

\author{
D. Moodley ${ }^{1,2,3}$, S. Geerts ${ }^{1,2,4}$, D. M. Richardson ${ }^{1}$ \& J. R. U. Wilson ${ }^{1,2}$ \\ 1 Department of Botany and Zoology, Centre for Invasion Biology, Stellenbosch University, Matieland, South Africa \\ 2 Invasive Species Programme, South African National Biodiversity Institute, Kirstenbosch National Botanical Gardens, Claremont, South Africa \\ 3 School of Agriculture, Earth and Environmental Science, University of KwaZulu-Natal, Durban, South Africa \\ 4 Department of Conservation and Marine Sciences, Cape Peninsula University of Technology, Cape Town, South Africa
}

\section{Keywords}

Biological invasions; breeding system; naturalisation; pollen limitation index; Proteaceae; South Africa.

\section{Correspondence}

D. Moodley, Department of Botany and Zoology, Centre for Invasion Biology, Stellenbosch University, Private Bag X1, Matieland 7602, South Africa.

E-mail: desikamoodley29@gmail.com

\section{Editor}

A. Dafni

Received: 18 August 2014; Accepted: 4 April 2015

doi:10.1111/plb.12334

\begin{abstract}
Reproduction is a crucial stage in the naturalisation of introduced plant species. Here, using breeding system experiments and observations of floral visitors, we investigate whether a lack of pollinators or an inability to autonomously self-fertilise limits naturalisation in five Australian Banksia species and the co-familial Hakea salicifolia in South Africa. Banksia species were heavily utilised by native insects and nectar-feeding birds. Although Banksia produced fruit when pollinators were excluded, pollinators significantly increased seed set in four of the five species. $H$. salicifolia flowers were visited by 11 insect species; honeybees (Apis mellifera) were the main visitors. Flowers in naturalised $H$. salicifolia populations received almost four times the number of visits as flowers in non-naturalised populations; the latter showed both pollen limitation (PLI 0.40) and partial self-incompatibility. This should not prevent invasion, since $H$. salicifolia produces fruits via autonomous selfing in the absence of pollinators. The results suggest a limited role of breeding systems in mediating naturalisation of introduced Proteaceae species. Other factors, such as features of the recipient environments, appear to be more important. Spatial variation in rates of reproduction might, however, explain variation in the extent and rate of naturalisation of different populations.
\end{abstract}

\section{INTRODUCTION}

Once an introduced species survives in a novel range, it needs to overcome a series of barriers to become naturalised and invasive (i.e., introduction-naturalisation-invasion continuum; Blackburn et al. 2011). One such barrier is reproduction (Barrett 2011; Correia et al. 2014). Alien plant species that rely on sexual reproduction must find a mate and a pollinator to reproduce and naturalise (Richardson et al. 2000a). Plant species that rely on outcrossing for population growth and spread need to attract floral visitors that transfer pollen. A lack of pollinators, or only partly effective pollinators, will result in pollen limitation, which could prevent or reduce the establishment and spread of introduced species (Parker 1997; Richardson et al. 2000a; Le Roux et al. 2010; Rodger et al. 2010; Bufford \& Daehler 2014).

In regions where pollinators are scarce or absent, plants that are capable of autonomous self-fertilisation have a higher chance of naturalising than self-incompatible species, as selffertilisation offers reproductive assurance (Baker's Law; Baker 1965; van Kleunen et al. 2008; Harmon-Threatt et al. 2009; Ward et al. 2012). Extending Baker's idea, self-incompatible species tend not to become invasive, whereas self-compatible species do (Rambuda \& Johnson 2004; van Kleunen \& Johnson 2007a; Hao et al. 2011). Moreover, self-compatible species occupy larger novel ranges than self-incompatible species (van Kleunen \& Johnson 2007b). However, more work is needed to establish the role of uniparental reproduction across various stages of the invasion process. For instance, does uniparental reproduction provide reproductive assurance during naturalisation (as originally envisaged by Baker)? Or is it primarily responsible for increasing spread rates by alleviating pollen limitation in small populations? Testing selfing capabilities and identifying the role of pollinators for alien species placed at different positions along the introduction-naturalisation-invasion (INI) continuum (sensu Richardson \& Pyšek 2012) will provide a better understanding of the importance of self-fertilisation in determining invasiveness.

Most studies on alien plant species that have assessed the importance of pollination and plant-pollinator interactions have focused on species that are already invasive (e.g., Rambuda \& Johnson 2004; van Kleunen \& Johnson 2007a; Rodger et al. 2010; Ward \& Johnson 2012). These species have already overcome the reproduction barrier, which confounds attempts to determine whether reproduction acts as a barrier to invasion (but see Stout et al. 2002; Bufford \& Daehler 2014). To understand the importance of uniparental reproduction and pollinator limitation as barriers for invasion, the different stages of plant invasions should be considered (Rambuda \& Johnson 2004). 
To minimise phylogenetic constraints, we use two genera within the family Proteaceae. Proteaceae provides an ideal study group to explore whether breeding system serves as a barrier to invasion. First, Proteaceae in general have low levels of self-compatibility (Horn 1962; Collins \& Spice 1986; Whelan \& Goldingay 1986; Goldingay et al. 1991; Ramsey \& Vaughton 1991; Goldingay \& Carthew 1998; Offord 2004; Rovere et al. 2006). Being largely self-incompatible, Proteaceae are therefore dependent on pollinators for seed production. Second, many Proteaceae are pollinated by only one functional group of pollinators (e.g., see Collins 1983; Collins \& Rebelo 1987; Rovere et al. 2006; Hanley et al. 2009). Third, there are relatively few naturalising and invasive Proteaceae species globally, but a large number of introduced Proteaceae species (Moodley et al. 2013). Proteaceae is currently underrepresented on the global list of invasive woody plants (Rejmánek \& Richardson 2013), probably because most introductions have been very recent; there is thus the possibility to prevent invasions before they occur. In South Africa, only eight out of 24 introduced species of Proteaceae are invasive, but with the exception of species of Grevillea R.Br. ex Knight, Hakea Schrad. \& J.C.Wendl. and Macadamia F. Muell., most species have only been introduced in small numbers (Geerts et al. 2013; Moodley et al. 2013, 2014).

In addition to comparing different species positioned at different invasion stages, comparisons conducted within one species (i.e., between naturalised and non-naturalised populations) in the introduced range could provide better insights into determinants of invasiveness. Such an approach specifically allows us to determine whether reproduction limits invasion, since there is control over other species-specific traits (e.g., pollination syndrome). Hakea salicifolia (Proteaceae) in South Africa presents such an opportunity, with many naturalised and non-naturalised populations scattered across the country (Moodley et al. 2014). More importantly, determining reproductive traits that confer invasiveness are crucial for understanding the drivers and limitations of invasions (Rambuda \& Johnson 2004).

Here, we aim to assess the importance of pollinators and autonomous selfing at the early stages of plant invasions using Australian Proteaceae species introduced into South Africa as a case study. Specifically, we aimed to determine (i) the ability of autonomous seed production versus pollinator contribution for five Banksia species along the introduction-naturalisationinvasion continuum; and (ii) whether breeding system and pollinators differ between naturalised and non-naturalised H. salicifolia populations.

\section{MATERIAL AND METHODS}

\section{Study sites and study species}

We selected one population each from two species that have not been recorded as having naturalised (B. coccinea and B. speciosa); two species that have been recorded as naturalised (B. serrata and B.formosa); and one species that has become invasive ( $B$. integrifolia). We also selected $H$. salicifolia as we could sample both naturalised and non-naturalised populations (Moodley et al. 2014). All populations studied were in the Western Cape Province of South Africa (see Table 1).
Banksia is a large genus of trees and shrubs, consisting of 172 species that are widespread in Australia (George 1999; Moodley et al. 2013). At least 11 species have been introduced into South Africa (Moodley et al. 2013). Most species produce showy inflorescences with copious amounts of nectar that attracts birds (George 1999). A few species are pollinated by insects or mammals (Carpenter 1978; Cunningham 1991). In South Africa, Banksia species usually set two seeds per capsule, except for B. formosa (R.Br.) A.R. Mast \& K.R. Thiele (formerly Dryandra formosa), which sets one seed per capsule (personal observation). Winged seeds are stored in woody follicles that open after fire (serotiny), with some species (e.g., B. formosa) releasing seeds upon maturity (George 1999; personal observation).

Banksia coccinea R.Br. has only been recorded from three sites in South Africa and has not been recorded as naturalised. The studied population in Elim comprised 48 individuals planted for cut flowers, and $\sim 3070$ seeds are stored in the canopy in veld that is 6 years old (Moodley et al. 2014). The second species examined that has not naturalised is B. speciosa R.Br., which has been recorded at seven sites. The studied population in Elim contained 29 planted trees for cut flower use and comprised a canopy seed bank of $\sim 37,500$ seeds in vegetation with a post-fire age of 11 years.

Banksia formosa (four populations in South Africa) and B. serrata L.f. (one population in South Africa) are recorded as naturalised. The B. formosa population in Elim selected for this study had 1978 individuals, planted for cut flowers. Seeds are produced in abundance (estimated $>26$ million seeds in the 10 year-old stand) and are released upon maturity (Moodley et al. 2014; personal observation). A single population of nine planted B. serrata trees in Betty's Bay, planted in natural fynbos, spread after the last fire and has a canopy seed bank of $\sim 180,000$ seeds. Although the age of this population could not be determined, the post-fire age of the veld is 14 years.

Lastly, nine B. integrifolia L.f. populations have been identified, of which at least one population, at Pringle Bay, is invasive. This population was selected for our pollinator observations and breeding system experiment. From a single tree planted in 1980, the population currently covers ca. 4 ha, with a canopy stored seed bank of around 750,000 seeds.

Hakea salicifolia is a large bushy shrub or small tree (Barker et al. 1999) native to southeast Queensland and eastern New South Wales in Australia. It has naturalised in several regions of the world (Moodley et al. 2013, 2014), including South Africa, where it was introduced around 1830 and is now widely used as an ornamental or hedge plant (Le Maitre et al. 2008). This species has recently been identified as naturalising in some sites, but not in others (Moodley et al. 2014). Of the 113 populations recorded in South Africa, 32 populations have naturalised (Moodley et al. 2014). For our study, we selected 16 populations comprising eight naturalised and eight non-naturalised populations.

In Australia H. salicifolia flowers between August and November (Barker et al. 1999), with a similar flowering phenology in South Africa (personal observation). Species belonging to the Hakea genus are visited by bees and wasps in their native range (Armstrong 1979), which is a relatively unspecialised pollination syndrome. This is followed by the development of two winged seeds enclosed in woody follicles (Barker et al. 1999). The wind-dispersed seeds are released after fire. 
Table 1. Locality details and number of self-sown alien Proteaceae in the Western Cape, South Africa, where pollination experiments were conducted.

\begin{tabular}{|c|c|c|c|c|c|c|c|c|}
\hline species & locality & latitude & longitude & $\begin{array}{l}\text { no. of } \\
\text { seedlings }\end{array}$ & $\begin{array}{l}\text { no. of } \\
\text { juveniles }\end{array}$ & $\begin{array}{l}\text { no. of mature } \\
\text { plants }\end{array}$ & $\begin{array}{l}\text { area of spreading } \\
\text { population }\left(\mathrm{m}^{2}\right)\end{array}$ & $\begin{array}{l}\text { population } \\
\text { status }^{\mathrm{a}}\end{array}$ \\
\hline Banksia speciosa & Blomkloof farm & -34.5376 & 19.8433 & 1 & 0 & 0 & 1842 & casual \\
\hline B. coccinea & Blomkloof farm & -34.6412 & 19.7076 & 0 & 0 & 0 & NA & casual \\
\hline B. formosa & Blomkloof farm & -34.5259 & 19.8124 & 27,100 & 6429 & 9989 & 19,781 & naturalised \\
\hline B. serrata & Bettys Bay & -34.3506 & 18.9213 & 10 & 34 & 11 & 2440 & naturalised \\
\hline B. integrifolia & Pringle Bay & -34.3532 & 18.8192 & 68 & 183 & 117 & 39,355 & invasive \\
\hline Hakea salicifolia & Grabouw & -34.2108 & 19.0433 & 103 & 44 & 16 & 608 & naturalised \\
\hline H. salicifolia & Tokai & -34.0609 & 18.4270 & 1611 & 29 & 1 & 23,842 & naturalised \\
\hline H. salicifolia & Paarl & -33.7331 & 19.0425 & 4304 & 910 & 38 & 2844 & naturalised \\
\hline H. salicifolia & Grabouw & -34.1761 & 19.0758 & 1693 & 135 & 30 & 2519 & naturalised \\
\hline H. salicifolia & Paarl & -33.7508 & 19.0376 & 2439 & 787 & 1 & 2296 & naturalised \\
\hline H. salicifolia & Klapmuts & -33.8336 & 18.8775 & 47 & 47 & 828 & 2367 & naturalised \\
\hline H. salicifolia & Theewaterskloof & -34.0171 & 19.2419 & 45,786 & 1886 & 10 & 6017 & naturalised \\
\hline H. salicifolia & Grabouw & -34.0749 & 19.0788 & 5081 & 4035 & 48 & 13,000 & naturalised \\
\hline H. salicifolia & Theewaterskloof & -34.0183 & 19.2373 & 12 & 12 & 0 & 604 & non-naturalised \\
\hline H. salicifolia & Citrusdal & -32.6101 & 18.9377 & 1 & 0 & 0 & 13,186 & non-naturalised \\
\hline H. salicifolia & Grabouw & -34.1595 & 19.0320 & 66 & 131 & 0 & 1232 & non-naturalised \\
\hline H. salicifolia & $\begin{array}{l}\text { Romansrivier } \\
\text { (near Wolseley) }\end{array}$ & -33.4933 & 19.1905 & 0 & 0 & 0 & NA & non-naturalised \\
\hline H. salicifolia & Paarl & -33.7343 & 19.0244 & 0 & 0 & 0 & NA & non-naturalised \\
\hline H. salicifolia & Stellenbosch & -33.9939 & 18.8270 & 0 & 0 & 0 & NA & non-naturalised \\
\hline H. salicifolia & Lynedoch & -33.9653 & 18.7971 & 0 & 0 & 0 & NA & non-naturalised \\
\hline H. salicifolia & Jonkershoek & -33.9600 & 18.9158 & 39 & 1 & 0 & 94 & non-naturalised \\
\hline
\end{tabular}

$\mathrm{NA}=$ populations where no seedlings, juveniles or mature plants where found, hence there are no data for area of spread.

Casual species do not form self-replacing populations and rely on repeated introductions for their persistence; naturalised species produce self-sown offspring that reproduce consistently without direct human intervention; invasive species are a subset of naturalised species that produce offspring at a considerable distance from the parent plant (>100 m over $<50$ years for taxa spreading by propagules; $>6 \mathrm{~m}$ over 3 years for taxa spreading by roots, rhizomes, stolons or creeping stems).

apopulation status classified according to Pyšek et al. (2004) and Richardson et al. (2000b).

Seed viability is generally high in Hakea, irrespective of follicle age (Richardson et al. 1987). However, seed viability declines in old H. salicifolia follicles (Richardson et al. 1987).

\section{Floral visitors}

Prior to observing visitors, all inflorescences visible from the vantage point (distance of $\sim 5 \mathrm{~m}$ ) were counted. We observed floral visits and scored visits as potential pollinator visits when there was contact with anthers or stigma. For each observation period, the identity of all pollinator species and the number of inflorescences visited were recorded. Pollinator visitation rates were quantified as the number of visits per inflorescence per hour. To standardise our sampling across sites, all observations were done in the morning, during similar weather conditions and by the same observer.

Starting at 09:30 h, we observed 30 inflorescences for $150 \mathrm{~min}$ over 2 days for B. speciosa (90 min on 12 July 2011; $60 \mathrm{~min}$ on 14 July 2011). A total of 185 B. integrifolia inflorescences were observed for 520 min over 2 days ( 205 min on 20 July 2011; $315 \mathrm{~min}$ on 22 July 2011). Observations were only done on two of the five Banksia species due to time constraints. Nevertheless, these species comprise a non-naturalised and invasive population status, which should represent visitation rates across the invasion continuum.

For H. salicifolia, we conducted floral visitor observations at six populations, $83 \mathrm{~min}$ of observations on 1650 inflorescences in two naturalised populations (23 min on 27 September 2012;
$60 \mathrm{~min}$ on 5 October 2012) and $207 \mathrm{~min}$ of observations on 3100 inflorescences in four non-naturalised populations (48 min on 28 September 2012; $60 \mathrm{~min}$ on 5 October 2012; $50 \mathrm{~min}$ on 5 October 2012; $49 \mathrm{~min}$ on 5 October 2012).

\section{Breeding systems}

To assess whether pollinators are important for reproduction in the introduced range, pollinator exclusion experiments were conducted to examine autonomous seed production. Pollen addition, hand- self- and hand cross-pollination experiments (described below) were conducted to assess the effectiveness of pollen supplementation and to determine whether pollen limitation restricts invasion.

We randomly assigned Banksia inflorescences to a natural or autonomous treatment (for sample sizes see Fig. 2). The autonomous treatment (Fig. 1a) involved bagging inflorescences that were still in bud phase using fine-mesh nylon bags. These bags prevented potential pollinators from accessing the inflorescences but were permeable to air and moisture. The natural treatment (Fig. 1b) served as the control; inflorescences were tagged at the base and left open for pollination. Each pair of autonomous and natural treatments was performed on the same plant.

For H. salicifolia, we selected between six and nine individuals at each of the naturalised and non-naturalised populations. We conducted five treatments: open or natural control (where flowers were left open to pollinators); open pollen addition 
Fig. 1. Aspects of the reproductive biology of Banksia and Hakea species in South Africa showing: a: Bagged $B$. integrifolia inflorescence; $b$ : Tagged $B$. formosa branch; c: Honeybee (Apis mellifera subsp. capensis) feeding on a $H$. salicifolia inflorescence; and d: Cape sugarbird (Promerops cafer) feeding on a $B$. speciosa inflorescence. Photographs: Sjirk Geerts and Desika Moodley.
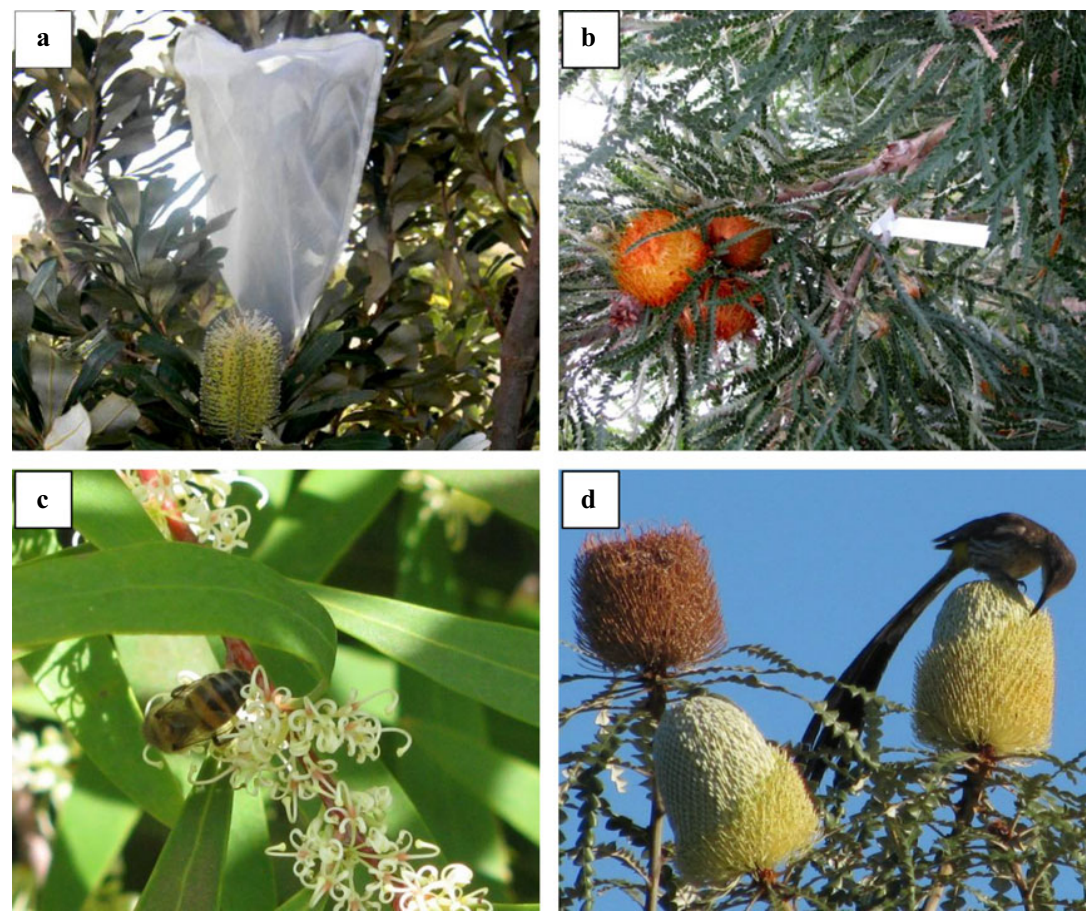

(open flowers were augmented with hand-pollination using pollen from donor plants located at least $5 \mathrm{~m}$ away); autonomous (flower buds were bagged and left); hand-crossed (flower buds were bagged and once mature were hand-pollinated with pollen from donor plants located at least $5 \mathrm{~m}$ away and carefully re-bagged); and hand-selfed (flower buds were bagged, and once receptive, were hand pollinated with pollen from other flowers of the same plant and carefully re-bagged). Prior to blooming, we visited all populations and tagged two branches (for the natural and open pollen addition experiments) and bagged three branches (for the autonomous, handcrossed, and hand-selfed treatments) on each plant. Branches were bagged with fine-mesh nylon bags to exclude potential pollinators. Hand-pollination treatments involved gently removing anthers from young flowers with clearly visible pollen using tweezers, and rubbing the pollen onto the stigma of the treated flower.

We documented the number of flowers for all treatments in order to measure the percentage fruit set (number of fruits produced/number of flowers $\times 100 \%$ ). All branches were harvested 4 weeks later. To identify the number of seeds produced per fruit, we dissected 1896 fruits (at most three fruits per treated plant). Since all dissected fruits contained two seeds, we subsequently only worked with the number of fruits produced.

\section{Data analysis}

All statistical analyses were conducted using R ( R Development Core Team 2012). Bootstrap means and confidence intervals (bias-corrected and accelerated intervals) were generated by performing 10,000 iterations of sampling with replacement using the 'boot' package.

For each Banksia species, we used a generalised linear model (GLM) with Poisson error to determine whether natural and autonomous treatments differed in the number of capsules set per inflorescence.
To test for differences in fruit production between all $H$. salicifolia populations and between the five treatments, we fitted a generalised linear mixed-effect model (GLMM) to allow for random effects caused by repetition of plants and populations. We also used a GLMM to test interaction effect between the treatments and naturalised and non-naturalised populations. Because we treated several flowers on each plant and several plants within each population, we used plant identity nested within population identity as a random effect. We applied the lmer function with a binomial error structure using the 'Ime4' package (Bates et al. 2012). Proportion fruit set was the response variable and the reproductive treatments (five levels) comprised the predictor variables.

We used two approaches to investigate the influence of breeding system on reproductive success between naturalised and non-naturalised populations. First, we estimated pollen limitation for naturalised and non-naturalised populations using the Pollen Limitation Index (PLI) proposed by Larson \& Barret (2000), where PLI $=[1-$ (natural fruit set/pollen supplementation fruit set)]; a value of zero indicates no pollen limitation. Second, following Lloyd \& Schoen (1992) we calculated self-compatibility indices (SCI) for the naturalised and non-naturalised populations, where $\mathrm{SCI}=$ seed set after hand-selfing/seed set after hand-crossing. Populations were considered partially self-incompatible if SCI was $<0.75$ and self-compatible if SCI $>0.75$. For both indices we calculated the average proportion of fruit set in each treatment per population status.

\section{RESULTS}

\section{Visitor observations}

Banksia speciosa and B. integrifolia were heavily utilised by native nectar-feeding birds and insects (Table 2), with B. speciosa receiving more than ten times as many visits per inflores- 
Table 2. Visitation rates to Banksia speciosa and B. integrifolia inflorescences in the Western Cape, South Africa.

\begin{tabular}{lll}
\hline & \multicolumn{2}{l}{ visits inflorescence ${ }^{-1} \cdot \mathrm{h}^{-1}$} \\
\cline { 2 - 3 } species & B. speciosa & B. integrifolia \\
\hline Apis mellifera subsp. capensis & 0.120 & 0.0118 \\
$\begin{array}{l}\text { Cinnyris chalybeus (lesser } \\
\text { double-collared sunbird) }\end{array}$ & 0.0800 & 0.00311 \\
Nectarinia famosa (malachite sunbird) & 0.120 & 0 \\
Promerops cafer (Cape sugarbird) & 0.0267 & 0.0100 \\
Zosterops pallidus (Cape white-eye) & 0 & 0.00249 \\
total & 0.347 & 0.0274 \\
\hline
\end{tabular}

cence per hour as B. integrifolia. H. salicifolia flowers were visited by 11 insect species, with similar species present at naturalised and non-naturalised populations (Table 3). Inflorescences were visited by bees, wasps, flies and beetles. Honeybees (Apis mellifera subsp. capensis Esch.) were the most frequent visitors across all sites and were frequently observed to be collecting nectar and thus foraging between flowers. In total, inflorescences in naturalised populations (0.15 visits inflorescence $^{-1} \cdot \mathrm{h}^{-1}$ ) were visited more frequently than inflorescences in non-naturalised populations $(0.04$ visits inflorescence $^{-1} \cdot \mathrm{h}^{-1}$ ), but this was not driven by a particular pollinator species (Table 3 ). In addition, during our extensive pollination experiments, pollinator species and frequencies were noted and found to correspond to the formal floral visitor observations.

\section{Breeding systems}

Banksia species produced high levels of autonomously self-pollinated seeds across all casual (B. coccinea and B. speciosa), naturalised (B. formosa and B. serrata) and invasive (B. integrifolia) species (Fig. 2). In addition, the number of capsules that set seed between the two treatments was significantly different for $B$. coccinea $(z=7.57, P<0.05)$, B. serrata $(\mathrm{z}=15.09, \quad P<0.01), \quad$ B. formosa $(\mathrm{z}=11.46, \quad P<0.01)$ and $B$. integrifolia ( $\mathrm{z}=17.98, P<0.01$ ), with the invasive $B$. integrifolia producing the largest number of capsules in both treatments. However, treatment did not have an effect on

Table 3. Floral visitors and visitation rates at naturalised and non-naturalised H. salicifolia populations in the Western Cape, South Africa.

\begin{tabular}{lll}
\hline & \multicolumn{2}{l}{ visits inflorescence ${ }^{-1} \cdot \mathrm{h}^{-1}$} \\
\cline { 2 - 3 } species & naturalised & non-naturalised \\
\hline Apis mellifera & 0.0858 & 0.0309 \\
Asarkina africana & 0.00652 & 0.00309 \\
Cardiotarsus acuminatus & 0.000466 & 0 \\
Chrysomya albiceps & 0.00140 & 0.00140 \\
Chrysomya marginalis & 0.00233 & 0.00168 \\
Dejeania bombylans & 0.00420 & 0 \\
Eristalinus taeniops & 0.00420 & 0.000281 \\
Musca domestica & 0.00326 & 0.000935 \\
Phytomia incisa & 0 & 0.00112 \\
Polistes fastidiosus & 0.00420 & 0.00159 \\
Scathophaga stercoraria & 0.0420 & 0.00102 \\
total & 0.154 & 0.0420 \\
\hline
\end{tabular}

B. speciosa, since the number of capsules set was similar between the autonomous and natural treatments $(\mathrm{z}=0.89$, $P=0.38)$. Overall, we only found a significant effect on handselfed and hand-crossed treatments between naturalised and non-naturalised $H$. salicifolia populations (Table S1). Furthermore, a comparison between pollination treatments and all populations combined revealed a significant treatment effect (Table S1). H. salicifolia produced significantly more fruits naturally than autonomously, but pollen addition significantly enhanced fruit production (Table 4, Fig. 3).

On average, more fruits were produced when pollen was added to flowers (mean for pollen addition: 95\% CI, 0.060; range $0.041-0.089$; mean for open control: 0.046 ; range $0.035-$ 0.062 ). This is especially evident in non-naturalised populations, where the average fruit set increased by more than $70 \%$ when pollen was added, as compared to $0 \%$ in naturalised populations. The PLI for all populations combined was 0.22 , but for non-naturalised populations was 0.40 , while naturalised populations were not pollen-limited (PLI of 0). Similarly, the hand-crossed and hand-selfed treatments showed significantly increased fruit set in non-naturalised populations (Table S1).

When we examined population status we also detected variation in self-compatibility between naturalised and nonnaturalised populations. Naturalised populations were strongly self-compatible (SCI 0.94), whereas non-naturalised populations were partially self-incompatible (SCI 0.71).

\section{DISCUSSION}

Species of Proteaceae introduced to South Africa are able to establish interactions with pollinators in their new range, but they also have the ability to set fruit autonomously without the intervention of pollinators. Pollen vectors increased fruit production in the studied Banksia and Hakea species. In its native range, $B$. coccinea and $B$. formosa have low levels of self-compatibility (Fuss \& Sedgley 1991; Matthews \& Sedgley 1998), however, the breeding systems of B. speciosa, B. serrata and $B$. integrifolia have not been evaluated. In South Africa, a lack of pollinators does not prevent the five Banksia species from producing fruits since all species can reproduce via autonomous self-pollination to some extent. This suggests that autonomous selfing in Banksia species is not related to naturalisation or invasion status. Across all H. salicifolia populations, the effect of additional pollen enhanced its reproductive output (Fig. 3), whereas between naturalised and non-naturalised populations self- and cross-pollination treatments significantly increased plant reproductive output (Table S1). This is one of very few detailed studies of the importance of pollinators and breeding systems at the early stages of plant invasion (Stout et al. 2002; van Kleunen et al. 2008). Here, we established that Australian Proteaceae introduced to South Africa attract similar pollinator guilds as in their native range, and that these bird and insect visitors play an important role in the reproductive performance of Proteaceae. However, whether this increase in reproductive success significantly increases population growth remains to be tested.

In its native range Banksia species are pollinated by several nectar-feeding bird species, insects, marsupials and rodents (Collins \& Rebelo 1987), and they attract sunbirds, sugarbirds and honeybees in South Africa. Our breeding system experiments and limited pollinator observations show that in South 


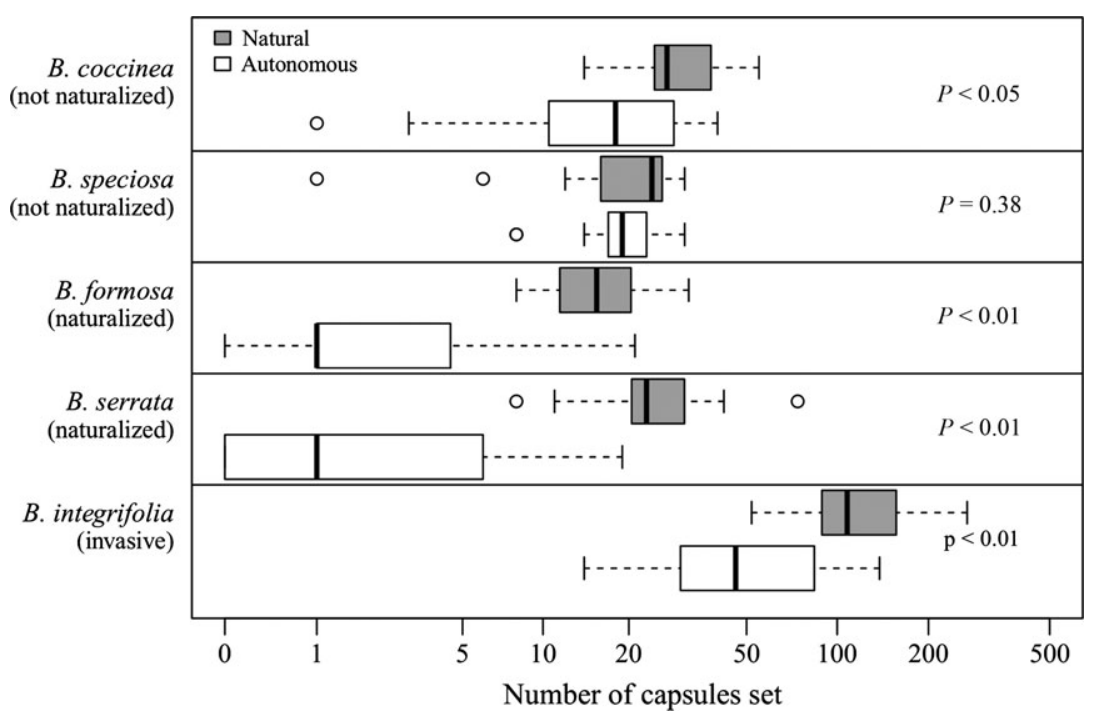

Fig. 2. Natural versus autonomous seed production in two casual (Banksia speciosa and B. coccinea), two naturalised ( $B$. formosa and $B$. serrata) and one invasive ( $B$. integrifolia) Banksia species, in the Western Cape, South Africa. Comparison of the number of capsules (log-transformed) produced between natural pollination ( $B$. coccinea, $\mathrm{n}=27 ; B$. speciosa, $\mathrm{n}=18 ; B$. formosa, $\mathrm{n}=20 ; B$. serrata, $\mathrm{n}=19 ; B$. integrifolia, $\mathrm{n}=20$ ) and autonomous treatments ( $B$. coccinea, $\mathrm{n}=27 ; B$. speciosa, $\mathrm{n}=19 ; B$. formosa, $\mathrm{n}=20 ; B$. serrata, $\mathrm{n}=18 ; B$. integrifolia, $\mathrm{n}=14$ ) was tested for each species (with significance levels provided for each species). All species produced significantly more capsules in pollinator-visited flowers (natural treatment), except for $B$. speciosa. Boxplots display the median with a solid line, 25th and 75th percentiles in the lower and upper boxes, respectively, and the data range is indicated by the whiskers. Open circles indicate outliers (values $>1.5$ times interquartile distance below 25th percentile).

Table 4. Average fruit set (i.e., proportion of flowers producing fruit) in H. salicifolia populations in the Western Cape, South Africa, across five pollination treatments. Sample sizes ( $n$ ) represent number of plants and flowers that were selected for each treatment.

\begin{tabular}{|c|c|c|c|}
\hline \multirow[b]{2}{*}{ treatment $(n)$} & \multicolumn{2}{|c|}{$\begin{array}{l}\text { proportion fruit set per flower } \\
\text { mean (range) }\end{array}$} & \multirow{2}{*}{$\begin{array}{l}\text { fruit set across } \\
\text { all sites } \\
\text { mean (range) }\end{array}$} \\
\hline & naturalised sites & $\begin{array}{l}\text { non-naturalised } \\
\text { sites }\end{array}$ & \\
\hline $\begin{array}{l}\text { natural } \\
(125 / 7754)\end{array}$ & $0.051(0-0.546)$ & $0.040(0-0.375)$ & $0.046(0-0.546)$ \\
\hline $\begin{array}{l}\text { autonomous } \\
(125 / 6732)\end{array}$ & $0.023(0-0.500)$ & $0.030(0-0.786)$ & $0.027(0-0.786)$ \\
\hline $\begin{array}{l}\text { pollen added } \\
(122 / 1857)\end{array}$ & $0.051(0-0.600)$ & $0.069(0-0.800)$ & $0.060(0-0.800)$ \\
\hline $\begin{array}{l}\text { cross } \\
(125 / 1309)\end{array}$ & $0.031(0-0.272)^{\mathrm{a}}$ & $0.062(0-0.750)^{\mathrm{b}}$ & $0.047(0-0.750)$ \\
\hline $\begin{array}{l}\text { self } \\
(126 / 1305)\end{array}$ & $0.030(0-0.286)^{\mathrm{a}}$ & $0.044(0-0.363)^{\mathrm{b}}$ & $0.037(0-0.363)$ \\
\hline
\end{tabular}

See Table S1 for the detailed statistical analyses.

$\mathrm{a}, \mathrm{b}$ Indicates a significant difference between naturalised and non-naturalised populations.

Africa these species set more seeds in the presence of pollinators. All Banksia species (except B. speciosa) showed a higher reliance on pollinators, but the invasive species demonstrated higher selfing capabilities. This provides support for Baker's Law (Baker 1955), which states that establishment is more likely for self-fertilising species, and also supports studies showing that pollinators can improve seed production in self-fertilising invasive species (Geerts \& Pauw 2009; Rodger et al. 2010). Similarly, the only known invasive $B$. ericifolia population in

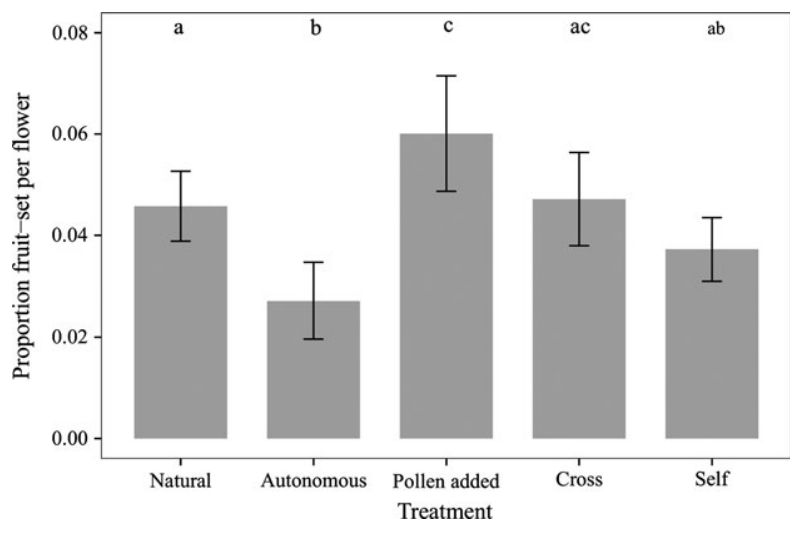

Fig. 3. The effects of five pollination treatments (natural, autonomous, pollen added, hand-crossed and hand-selfed) on the average fruit to flower ratio in all Hakea salicifolia populations (i.e., naturalised and non-naturalised populations combined). Error bars depict SE of means.

South Africa, although self-compatible, relies on native nectarfeeding birds and honeybees to maintain its population (Geerts et al. 2013). Many widely recognised invasive plants are well integrated into pollination networks in their introduced range (Olesen et al. 2002; Morales \& Aizen 2006). However, if these Banksia species are introduced to regions without nectar-feeding birds, we would expect seed production to be lower and the chance of invasion to be significantly lower (see Ollerton et al. 2012 for regions with no specialised nectar feeders). Nevertheless, the invasive Banksia was still the most successful species, even in the absence of pollinators.

The ability of plants to attract suitable pollinators that are efficient in transferring pollen determines reproductive success 
(Harder \& Barrett 2006; Mitchell et al. 2009). Honeybees were the most frequent visitors to $H$. salicifolia inflorescences (i.e., 59\% of visits were made by honeybees). Moreover, reproduction will be maintained in regions where this generalist pollinator occurs (Rodger et al. 2010). The PLI revealed that non-naturalised populations were pollen-limited and appear to be partially self-incompatible (i.e., SCI), thereby requiring some degree of cross-pollination to significantly enhance set seed (Table S1). Pollen quantity may be limiting when plants compete for the services of pollinators (i.e., Allee effects; Groom 1998; Cappuccino 2004; Davis et al. 2004). Pollinator visitation rates can influence whether populations naturalise or not (Razanajatovo et al. 2015). We found that visitation rates are more than three times higher in naturalised H. salicifolia sites than non-naturalised populations. Lower fruit production in non-naturalised populations can therefore be explained by pollen limitation. Two naturalised populations were surrounded with vineyards and orchards, whereas the four non-naturalised populations were planted close to a vineyard, along a road, in pastoral land, and along an old orchard (Tables 1 and 4). The presence of many fruit trees increases the number of insect visitors and this probably explains why populations surrounded by fruit trees have more visitors. Pollen limitation and self-incompatibility may not restrict non-naturalised $H$. salicifolia populations from spreading, but could partly explain why some populations have not yet naturalised. For example, the rate of spread in Cytisus scoparius along the west coast of North America was reduced due to pollen limitation, but the species still became a widespread invader (Parker 1997).

Studies on other invasive plant species have also demonstrated that self-compatibility and suitable pollinators in the introduced range are important for successful invasions (Rambuda \& Johnson 2004; van Kleunen \& Johnson 2005, 2007a; van Kleunen et al. 2008; Rodger et al. 2010; Pyšek et al. 2011; Ward \& Johnson 2012). Our study adds to the sparse literature on self-compatibility in invasive woody plants. Self-compatibility is clearly not a prerequisite for invasion, and self-incompatible species can become successful invaders. Pollinator limitation and self-incompatibility will lower seed production and perhaps slow down population expansion, but it will not prevent it (Richardson et al. 2000a; Traveset \& Richardson 2006). As such, except for the advantage of legitimate self- and cross-pollen transfer, our results do not show a strong role for reproduction in explaining plant invasions. Rather, characteristics related to species traits (e.g., serotiny and native range size; Moodley et al. 2013) and invasibility (e.g., phylogenetic novelty; Burns et al. 2011) and the reason for introduction appear to be the key drivers of these invasions.

Studies that focus on the mechanisms that limit invasions have the potential to provide practical guidelines for risk assessment and management (e.g., Bufford \& Daehler 2014). In the cases examined here, a lack of floral visitors could result in a lag phase and might reduce rates of spread, but are unlikely to completely prevent invasions. We suspect that research comparing the breeding systems of populations of introduced woody species at different stages of the invasion process will continue to provide important practical insights. With an increasing number of such empirical studies, it should also become possible to demonstrate when and where Baker's Law applies.

\section{ACKNOWLEDGEMENTS}

We are grateful to Anina Heystek, Ethan Newman, Mashudu Mashau, Pieter Botha and Elisabeth Geerts for assistance with fieldwork. We thank all the landowners who gave us permission to work on their property, especially Andre Brink of Blomkloof flower farm in Elim. This work was funded by the Working for Water (WfW) Programme of the South African Department of Environmental Affairs through the South African National Biodiversity Institute's Invasive Species Programme and the DST-NRF Centre of Excellence for Invasion Biology. SG and DMR acknowledge support from the National Research Foundation (grants 75213, 87843 and 85417, respectively).

\section{SUPPORTING INFORMATION}

Additional Supporting Information may be found in the online version of this article:

Table S1. Results of GLMM, testing the effect of five treatments on $H$. salicifolia fruit set (i.e., between all populations combined) and the interaction between the treatments and population status (i.e., between naturalised and non-naturalised populations).

\section{REFERENCES}

Armstrong J.A. (1979) Biotic pollination mechanisms in the Australian flora - a review. New Zealand Journal of Botany, 17, 467-508.

Baker H.G. (1955) Self-compatibility and establishment after 'long distance' dispersal. Evolution, 9, 347-349.

Baker H.G. (1965) Characteristics and modes of origin of weeds. In: Baker H.G., Stebbins G.L. (Eds), The genetics of colonising species. Academic Press, New York, NY, USA.

Barker R.M., Haegi L., Barker W.R. (1999) Hakea. In: Wilson A. (Ed.), Flora of Australia: Proteaceae $3 \mathrm{Ha}$ kea to Dryandra. Australian Biological Resources Study, CSIRO Publishing, Canberra, ACT, Australia, pp 416.

Barrett S.C.H. (2011) Why reproductive systems matter for the invasion biology of plants. In: Richardson
D.M. (Ed.), Fifty years of invasion ecology: the legacy of Charles Elton. Wiley-Blackwell, Oxford, UK, pp 195-210.

Bates D., Maechler M., Bolker B. (2012) lme4: Linear mixed-effects models using S4 classes. Available from: http://CRAN.R-project.org/package=lme4 (accessed 1 September 2012).

Blackburn T., Pyšek P., Bacher S., Carlton J., Duncan R., Jarošík V., Wilson J., Richardson D. (2011) A proposed unified framework for biological invasions. Trends in Ecology \& Evolution, 26, 333-339.

Bufford J.L., Daehler C.C. (2014) Sterility and lack of pollinator services explain reproductive failure in noninvasive ornamental plants. Diversity and Distributions, 20, 975-985.

Burns J.H., Ashman T.L., Steets J.A., Harmon-Threatt A., Knight T.M. (2011) A phylogenetically controlled analysis of the roles of reproductive traits in plant invasions. Oecologia, 166, 1009-1017.
Cappuccino N. (2004) Allee effect in an invasive alien plant, pale swallowwort Vincetoxicum rossicum (Asclepiadaceae). Oikos, 106, 3-8.

Carpenter F.L. (1978) Hooks for mammal pollination? Oecologia, 35, 123-132.

Collins B.G. (1983) Pollination of Mimetes hirtus (Proteaceae) by Cape sugarbirds and orange-breasted sunbirds. Journal of South African Botany, 49, 125-142.

Collins B., Rebelo T. (1987) Pollination biology of the Proteaceae in Australia and Southern Africa. Australian Journal of Ecology, 12, 387-421.

Collins B.G., Spice J. (1986) Honeyeaters and the pollination biology of Banksia prionotes (Proteaceae). Australian Journal of Botany, 34, 175-185.

Correia M., Castro S., Ferrero V., Crisóstomo J.A., Rodríguez-Echeverría S. (2014) Reproductive biology and success of invasive Australian acacias in Portugal. Botanical Journal of the Linnean Society, 174, 574-588. 
Cunningham S.A. (1991) Experimental evidence for pollination of Banksia spp. by non-flying mammals. Oecologia, 87, 86-90.

Davis H.G., Taylor C.M., Civille J.C., Strong D.R. (2004) An Allee effect at the front of a plant invasion: Spartina in a Pacific estuary. Journal of Ecology, 92, 321-327.

Fuss A.M., Sedgley M. (1991) Pollen tube growth and seed set of Banksia coccinea R.Br. (Proteaceae). Annals of Botany, 68, 377-384.

Geerts S., Pauw A. (2009) African sunbirds hover to pollinate an invasive hummingbird-pollinated plant. Oikos, 118, 573-579.

Geerts S., Moodley D., Gaertner M., Le Roux J.J., McGeoch M.A., Muofhe C., Richardson D.M., Wilson J.R.U. (2013) The absence of fire can cause a lag phase: the invasion dynamics of Banksia ericifolia (Proteaceae). Austral Ecology, 38, 931-941.

George A.S. (1999) Banksia. In: Orchard A.E., Thompson H.S., McCarthy P.M. (Eds), Flora of Australia: Proteaceae 3 Hakea to Dryandra. Australian Biological Resources Study, CSIRO Publishing, Canberra, ACT, Australia, pp 416.

Goldingay R.L., Carthew S.M. (1998) Breeding and mating systems of Australian Proteaceae. Australian Journal of Botany, 46, 421-437.

Goldingay R.L., Schibeci S.M., Walker B.A. (1991) Breeding system and pollination levels of Banksia ericifolia. Australian Journal of Botany, 39, 365-372.

Groom M.J. (1998) Allee effects limit population viability of an annual plant. The American Naturalist, 151, 487-496.

Hanley M.E., Lamont B.B., Armbruster W.S. (2009) Pollination and plant defence traits co-vary in Western Australian Hakeas. New Phytologist, 182, 251260.

Hao J.H., Qiang S., Chrobock T., van Kleunen M., Liu Q.Q. (2011) A test of Baker's law: breeding systems of invasive species of Asteraceae in China. Biological Invasions, 13, 571-580.

Harder L.D., Barrett S.C.H. (2006) Ecology and evolution of flowers. Oxford University Press, Oxford, UK, pp 384.

Harmon-Threatt A.N., Burns J.H., Shemyakina L.A., Knight T.M. (2009) Breeding system and pollination ecology of introduced plants compared to their native relatives. American Journal of Botany, 96, $1544-1550$

Horn W. (1962) Breeding research on South African plants: II. Fertility of Proteaceae. Journal of South African Botany, 28, 259-268.

van Kleunen M., Johnson S.D. (2005) Testing for ecological and genetic Allee effects in the invasive shrub Senna didymobotrya (Fabaceae). American Journal of Botany, 92, 1124-1130.

van Kleunen M., Johnson S.D. (2007a) Effects of selfcompatibility on the distribution range of invasive European plants in North America. Conservation Biology, 21, 1537-1544.

van Kleunen M., Johnson S.D. (2007b) South African Iridaceae with rapid and profuse seedling emergence are more likely to become naturalized in other regions. Journal of Ecology, 95, 674-681.

van Kleunen M., Manning J.C., Pasqualetto V., Johnson S.D. (2008) Phylogenetically independent associ- ations between autonomous self-fertilization and plant invasiveness. The American Naturalist, 171 195-201.

Larson B.M.H., Barret S.C.H. (2000) A comparative analysis of pollen limitation in flowering plants. Biological Journal of the Linnean Society, 69, 503-520.

Le Maitre D.C., Thuiller W., Schonegevel L. (2008) Developing an approach to defining the potential distributions of invasive plant species: a case study of Hakea species in South Africa. Global Ecology and Biogeography, 17, 569-584.

Le Roux J.J., Geerts S., Ivey P., Krauss S., Richardson D.M., Suda J., Wilson J.R.U. (2010) Molecular systematics and ecology of invasive Kangaroo Paws in South Africa: management implications for a horticulturally important genus. Biological Invasions, 12, 3989-4002.

Lloyd D.G., Schoen D.J. (1992) Self-fertilization and cross-fertilization in plants. 1. Functional dimensions. International Journal of Plant Sciences, 153 358-369.

Matthews M.L., Sedgley M. (1998) Breeding system of Dryandra quercifolia and D. formosa (Proteaceae). Australian Journal of Botany, 46, 439-452.

Mitchell R.J., Irwin R.E., Flanagan R.J., Karron J.D. (2009) Ecology and evolution of plant-pollinator interactions. Annals of Botany, 103, 1355-1363.

Moodley D., Geerts S., Richardson D.M., Wilson J.R.U. (2013) Different traits determine introduction, naturalization and invasion success in woody plants: Proteaceae as a test case. PLoS One, 8, e75078.

Moodley D., Geerts S., Rebelo T., Richardson D.M., Wilson J.R.U. (2014) Site-specific conditions influence plant naturalization: the case of alien Proteaceae in South Africa. Acta Oecologica, 59, 62-71.

Morales C.L., Aizen M.A. (2006) Invasive mutualisms and the structure of plant-pollinator interactions in the temperate forests of north-west Patagonia, Argentina. Journal of Ecology, 94, 171-180.

Offord C.A. (2004) An examination of the reproductive biology of Telopea speciosissima (Proteaceae) with emphasis on the nature of protandry and the role of self-pollination in fruit set. International Journal of Plant Sciences, 165, 73-83.

Olesen J.M., Eskildsen L.I., Venkatasamy S. (2002) Invasion of pollination networks on oceanic islands: importance of invader complexes and endemic super generalists. Diversity and Distributions, 8, 181-192.

Ollerton J., Watts S., Connerty S., Lock J., Parker L., Wilson I., Schueller S., Nattero J., Cocucci A.A., Izhaki I., Geerts S., Pauw A., Stout J.C. (2012) Pollination ecology of the invasive tree tobacco Nicotiana glauca: comparisons across native and non-native ranges. Journal of Pollination Ecology, 9, 85-95.

Parker I.M. (1997) Pollinator limitation of Cytisus scoparius (Scotch broom), an invasive exotic shrub. Ecology, 78, 1457-1470.

Pyšek P., Richardson D.M., Rejmánek M., Webster G.L., Williamson M., Kirschner J. (2004) Alien plants in checklists and floras: towards better communication between taxonomists and ecologists. Taxon, 53, 131-143.

Pyšek P., Jarošik V., Chytrý M., Danihelka J., Kühn I., Pergl J., Tichý L., Biesmeijer J.C., Ellis W.N., Kunin
W.E., Settele J. (2011) Successful invaders co-opt pollinators of native flora and accumulate insect pollinators with increasing residence time. Ecological Monographs, 81, 277-293.

R Development Core Team (2012) R: a language and environment for statistical computing, R Foundation for Statistical Computing, Vienna, Austria. Available from: http://www.R-project.org/.

Rambuda T.D., Johnson S.D. (2004) Breeding systems of invasive alien plants in South Africa: does Baker's rule apply? Diversity and Distributions, 10, 409-416.

Ramsey M., Vaughton G. (1991) Self-incompatibility, protandry, pollen production and pollen longevity in Banksia menziesii. Australian Journal of Botany, 39, 497-504.

Razanajatovo M., Föhr C., Fischer M., Prati D., van Kleunen M. (2015) Non-naturalized alien plants receive fewer flower visits than naturalized and native plants in a Swiss botanical garden. Biological Conservation, 182, 109-116.

Rejmánek M., Richardson D.M. (2013) Trees and shrubs as invasive alien species - 2013 update of the global database. Diversity and Distributions, 19, 1093-1094.

Richardson D.M., Pyšek P. (2012) Naturalization of introduced plants: ecological drivers of biogeographical patterns. New Phytologist, 196, 383-396.

Richardson D.M., Van Wilgen B.W., Mitchell D.T. (1987) Aspects of the reproductive ecology of four Australian Hakea species (Proteaceae) in South Africa. Oecologia, 71, 345-354.

Richardson D.M., Allsopp N., D’Antonio C.M., Milton S.J., Rejmánek M. (2000a) Plant invasions - the role of mutualisms. Biological Reviews, 75, 65-93.

Richardson D.M., Pyšek P., Rejmánek M., Barbour M.G., Panetta F.D., West C.J. (2000b) Naturalization and invasion of alien plants: concepts and definitions. Diversity and Distributions, 6, 93-107.

Rodger J.G., van Kleunen M., Johnson S.D. (2010) Does specialized pollination impede plant invasions? International Journal of Plant Sciences, 171, 382-391.

Rovere A.E., Smith-Ramírez C., Armesto J.J., Premoli A.C. (2006) Breeding system of Embothrium coccineum (Proteaceae) in two populations on different slopes of the Andes. Revista Chilena de Historia Natural, 79, 225-232.

Stout J.C., Kells A.R., Goulson D. (2002) Pollination of the invasive exotic shrub Lupinus arboreus (Fabaceae) by introduced bees in Tasmania. Biological Conservation, 106, 425-434.

Traveset A., Richardson D.M. (2006) Biological invasions as disruptors of plant reproductive mutualism. Trends in Ecology \& Evolution, 21, 208-216.

Ward M., Johnson S.D. (2012) Generalised pollination systems for three invasive milkweeds in Australia. Plant Biology, 15, 566-572.

Ward M., Johnson S.D., Zalucki M.P. (2012) Modes of reproduction in three invasive milkweeds are consistent with Baker's Rule. Biological Invasions, 14, 1237-1250.

Whelan R.J., Goldingay R.L. (1986) Do pollinators influence seed-set in Banksia paludosa Sm. and Banksia spinulosa R. Br.? Australian Journal of Ecology, 11, 181-186. 
1 Table S1. Results of generalized linear mixed-effect models, testing the effect of five 2 treatments on Hakea salicifolia fruit set (i.e. between all populations combined) and the 3 interaction between the treatments and population status (i.e. between naturalized and non4 naturalized populations). Plant identity nested within population identity was considered as a

5 random factor. We used the relevel function to test the effect between all treatments.

\begin{tabular}{lcccc}
\hline Fixed effects / response variables & Estimate & $\begin{array}{c}\text { Std. } \\
\text { Error }\end{array}$ & $\begin{array}{c}\mathbf{Z}- \\
\text { value }\end{array}$ & $\operatorname{Pr}(>|\mathbf{z}|)$ \\
\hline Natural & & & & \\
Natural x Autonomous & -0.392 & 0.097 & -4.057 & $\mathrm{P}<0.0001^{* * *}$ \\
Natural x Pollen added & 0.350 & 0.126 & 2.775 & $0.00552^{* * *}$ \\
Natural x Cross & 0.096 & 0.146 & 0.655 & 0.512 \\
Natural x Self & -0.086 & 0.157 & -0.550 & 0.582 \\
Natural x Status & 0.080 & 0.154 & 0.521 & 0.603 \\
Autonomous & & & & \\
Autonomous x Pollen added & 0.741 & 0.132 & 5.631 & $\mathrm{P}<0.0001 * * *$ \\
Autonomous x Cross & 0.488 & 0.152 & 3.219 & $0.00129 * *$ \\
Autonomous x Self & 0.306 & 0.163 & 1.879 & 0.060 \\
Autonomous x Status & 0.276 & 0.184 & 1.502 & 0.133 \\
Pollen added & & & & \\
Pollen added x Cross & -0.254 & 0.170 & -1.494 & 0.135 \\
Pollen added x Self & -0.436 & 0.180 & -2.426 & $0.0152^{*}$ \\
Pollen added x Status & 0.402 & 0.237 & 1.701 & 0.089 \\
Cross & & & & \\
Cross x Self & -0.182 & 0.195 & -0.935 & 0.350 \\
Cross x Status & 0.917 & 0.289 & 3.170 & $0.00152^{* *}$ \\
Self & & & & \\
Self x Status & 0.730 & 0.310 & 2.352 & $0.0187^{*}$ \\
\hline
\end{tabular}

$* P<0.01 ; * * P<0.001 ; * * * P<0.0001$ 


\begin{tabular}{lcccc}
\hline Fixed effects / response variables & Estimate & Std. Error & z-value & $\operatorname{Pr}(>|\mathbf{z}|)$ \\
\hline Natural & & & & \\
Natural x Autonomous & -0.392 & 0.097 & -4.057 & $\mathrm{P}<0.0001^{* * *}$ \\
Natural x Pollen added & 0.350 & 0.126 & 2.775 & $0.00552^{* * *}$ \\
Natural x Cross & 0.096 & 0.146 & 0.655 & 0.512 \\
Natural x Self & -0.086 & 0.157 & -0.550 & 0.582 \\
Natural x Status & 0.080 & 0.154 & 0.521 & 0.603 \\
Autonomous & & & & \\
Autonomous x Pollen added & 0.741 & 0.132 & 5.631 & $\mathrm{P}<0.0001 * * *$ \\
Autonomous x Cross & 0.488 & 0.152 & 3.219 & $0.00129 * *$ \\
Autonomous x Self & 0.306 & 0.163 & 1.879 & 0.060 \\
Autonomous x Status & 0.276 & 0.184 & 1.502 & 0.133 \\
Pollen added & & & & \\
Pollen added x Cross & -0.254 & 0.170 & -1.494 & 0.135 \\
Pollen added x Self & -0.436 & 0.180 & -2.426 & $0.0152^{*}$ \\
Pollen added x Status & 0.402 & 0.237 & 1.701 & 0.089 \\
Cross & & & & \\
Cross x Self & -0.182 & 0.195 & -0.935 & 0.350 \\
Cross x Status & 0.917 & 0.289 & 3.170 & $0.00152^{* *}$ \\
Self & & & & \\
Self x Status & 0.730 & 0.310 & 2.352 & $0.0187^{*}$ \\
\hline P $<0.01 ; * P<0.001 ; * * P<0.0001$ & & &
\end{tabular}

$* P<0.01 ; * * P<0.001 ; * * * P<0.0001$ 